\title{
RECURRENT ABDOMINAL PAINS : A FIELD SURVEY OF 1,000 SCHOOL CHILDREN
}

\author{
BY \\ JOHN APLEY and NORA NAISH \\ From the United Bristol Hospitals
}

(RECEIVED FOR PUBLICATION AUGUST 16, 1957)

What sort of children are they who complain of recurrent abdominal pains, and how do they compare with children who do not suffer from such pains? Because patients referred to hospital are inevitably pre-selected, we have tried to answer these questions by a survey of 1,000 unselected children at primary and secondary modern schools.

One of us throughout the survey, and sometimes both, attended routine school medical examinations at Bristol from January, 1955, to June, 1956. A few children not accompanied by a parent were excluded; the remainder were asked if they suffered from bouts of abdominal pain.

\section{Nature of Investigation}

Children with Pains. In our series we included every child who had had at least three bouts of pain, severe enough to affect his activities, over a period of not less than three months, with attacks continuing in the year preceding the examination. In taking the history, which was obtained from the mother as well as the child, we went into considerable detail regarding home life and the family as well as the child's personal history. The school headmasters and headmistresses helped greatly by providing reports on behaviour, intelligence and attainments.

Children with pains were examined clinically, but ancillary investigations were not undertaken (it is intended to publish separately a complementary investigation of hospital cases). The single exception was electro-encephalography (E.E.G.), for which facilities were made available at a convenient centre.

Control Series. Detailed information on the same lines, i.e., personal and family history, as well as clinical examination and E.E.G., was obtained from a proportion of the children living in the same districts and attending the same school medical examinations, but not found to be complaining of abdominal pains. As a rule the child who happened to be next on the list after one with pains was chosen for the control series. The numbers were, however, considerably increased by adding further children as often as time permitted, and by including a small number of those below school age who by chance had come with their mothers.

\section{Incidence}

When 1,000 children with their mothers had been questioned the investigation was stopped. The numbers obtained are summarized in Table 1.

TABLE 1

CASE MATERIAL

\begin{tabular}{|c|c|c|c|}
\hline & Total & Boys & Girls \\
\hline Preliminary Questioning & 1,000 & 528 & 472 \\
\hline 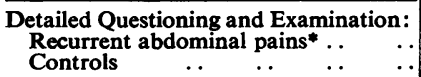 & $\begin{array}{l}108 \\
312\end{array}$ & $\begin{array}{r}50 \\
155\end{array}$ & $\begin{array}{r}58 \\
157\end{array}$ \\
\hline
\end{tabular}

- Thirteen children whose pains had ceased more than a year previously have been excluded here and from the calculations of incidence.

Of the total, $10 \cdot 8 \%$ had recurrent abdominal pains fulfilling our criteria. Girls were affected more often than boys $(12 \cdot 3 \%$ to $9 \cdot 5 \%)$.

Age Distribution. There was considerable variation in the incidence of pains at different ages (Fig. 1). There were no complaints of pains in the small number of children below 5 years of age. In boys from 5 to 10 years of age there was a steady incidence of between $10 \%$ and $12 \%$, followed after a fall by a late peak at 14 years. In girls the incidence was similar up to the age of 8 years. This was, however, followed by a marked rise, with more than a quarter of all girls of 9 years affected, and subsequently a steady decrease.

Age of Onset. The age of onset of the pains in 118 children is illustrated in Fig. 2. (The total of 
118 is made up of 108 children with continuing pains and 13 in whom pains had ceased more than a year previously, less three in whom the age of onset was not known.)

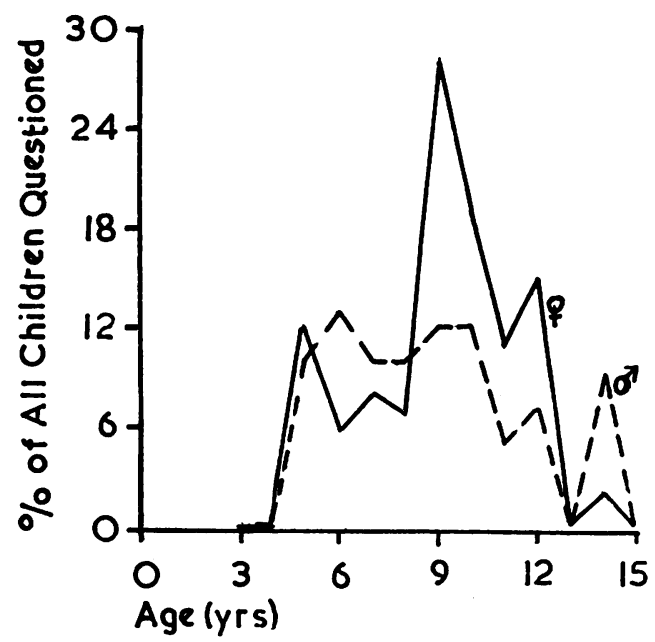

Fig. 1.-Proportion of children affected at each year of age.

In both boys and girls there was a steady rise up to the age of 5 years. In the boys the numbers then fell; but in the girls there was a further striking rise, with pains commencing in a large proportion between 8 and 10 years of age, and none subsequently.



FIG. 2.-Age of onset of pains. (118 children: 57 boys, 61 girls.)

\section{The Pains}

A full description of variations in the characteristics of the pains will not be given here. We have found elsewhere (unpublished hospital data) that an accurate description of pain in children is more likely to be obtained during attacks than in the intervals.

In brief, it seemed that in some two-thirds of the children the pain was felt at or round the umbilicus. With only a few exceptions, it occurred in the midepigastrium among the remainder. In about a quarter it was severe. The time of occurrence varied greatly. The duration of the pain showed great variability from case to case, and from one bout to another in most children. The frequency of occurrence also varied considerably, from those with a rare (often severe) episode to those who said they nearly always had some (usually mild) pain. About one-fifth showed a tendency to periodicity.

The pains were attributed to many factors. The most common were excitement, worry or 'being worked up', feelings often associated with schooling. One girl had a severe attack on the day after she lost a pound note which a neighbour gave her to buy cigarettes. As 'cures', soda-water, defaecation and the doctor's medicine came low in the list. Rest was often thought helpful, but in most cases the pains just got better.

Table 2 summarizes the disturbances associated with attacks of pain.

TABLE 2

DISTURBANCES ASSOCIATED WITH ATTACKS OF PAIN

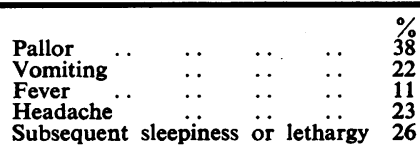

The association was scored only if it occurred commonly or invariably. Several might occur together, and in a fifth of the cases (often those with severer pains) the combination of abdominal pain, vomiting and headache, and sometimes fever, was recorded. There were in addition 13 children who had bouts of headache and vomiting without abdominal pains.

As between the isolated abdominal pain and the combination of many disturbances, there seemed to be a gradation from case to case, which made any clear-cut grouping unprofitable. In any individual child the pattern tended, however, to be more or less constant, though with occasional variations in severity.

\section{Family History}

The child is an inseparable part of his family, and we were particularly interested in comparing the families of children with pains against those without pains. Table 3 summarizes some relevant data from the family histories. 
TABLE 3

DATA FROM FAMILY HISTORIES

\begin{tabular}{|c|c|c|}
\hline $\begin{array}{c}\text { Complaints of other Members } \\
\text { of Family }\end{array}$ & $\begin{array}{l}\text { Percen } \\
\text { With Pains }\end{array}$ & $\begin{array}{l}\text { in Children } \\
\text { Without Pains }\end{array}$ \\
\hline 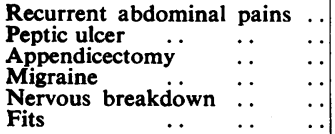 & $\begin{array}{r}46 \\
10 \\
8 \\
14 \\
10 \\
6\end{array}$ & $\begin{array}{l}\mathbf{8} \\
\mathbf{3} \\
\mathbf{3} \\
\mathbf{3} \\
\mathbf{2} \\
\mathbf{3}\end{array}$ \\
\hline
\end{tabular}

We have included only the immediate family, i.e., parents and siblings, though the data of more distant relations showed similar trends. In the diagnoses listed we have not attempted to be precise, since the sources of our information were nonmedical. Thus, under 'peptic ulcer' we included only those in whom there was said to have been a haematemesis or operation, or radiographic confirmation; under 'migraine' we included all severe headaches; and under 'nervous breakdown' disorders severe enough to have caused a serious disruption of normal life. Mothers accounted for two-fifths of those members of the family affected by recurrent abdominal pains, fathers a slightly smaller proportion, and brothers and sisters the remainder.

A marked preponderance of the disorders listed was found in the families of children with abdominal pains, though the figures for 'fits' are too small to be statistically significant. It is clear that the families of these children have an enhanced tendency to abdominal and 'nervous' disorders. In other respects, including psychosis and serious behaviour disorders, the numbers were very small and we found no obvious differences from the controls.

An additional item was the proportion of 'broken homes', i.e., where one or other parent was dead, or had left home, or there had been a divorce or legal separation. We recorded a 'broken home' in $4 \%$ of the children with pains, as, rather unexpectedly, against $7 \%$ of the controls.

\section{Child's History}

Some noteworthy differences also emerged when we compared the histories of children with and without abdominal pains (Table 4).

TABLE 4

DATA FROM PERSONAL HISTORIES

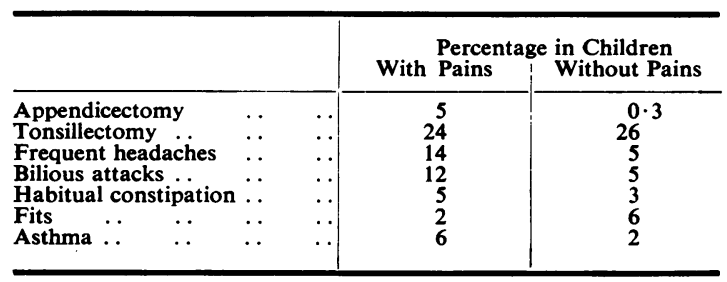

Appendicectomy in the control series was rare (1 in 312). The histories of five children with recurrent abdominal pains in whom appendicectomy was performed were obtained and are summarized herewith.

Case 1. Colicky pains for nine months. 'Normal looking appendix' removed. Pains recurred.

Case 2. Pains for several months. Operation because of tenderness in $\mathbf{R}$. iliac fossa. Normal appendix removed. Pains recurred.

Case 3. Pains for several years. 'Mildly infected appendix' removed. No further pains when seen two years later.

Case 4. No previous pains. Operation at 2 years of age. Acutely inflamed appendix (and pelvic abscess) removed. Recurrent abdominal pains during the ensuing seven years.

Case 5. Four attacks of abdominal pain in two years. In the fifth attack pain became localized for the first time to the R. iliac fossa, with overlying rigidity. Acutely inflamed retro-caecal appendix removed. No further information available.

Tonsillectomy was the only other operation done with any frequency; the incidence was almost identical in the two groups.

The children with abdominal pains suffered more than the controls from headaches and from so-called bilious attacks. The comparative figures for constipation, fits, asthma and allergic conditions in general were too small to warrant conclusions. The history of other physical disorders showed no significant differences between the two groups.

\section{Physical Assessment}

We assessed the children of both groups by recording items like physique, posture, height, weight, colouring, palpable lymph nodes, condition of the teeth and tongue, and all abnormalities found on routine clinical examination. The average weights of the younger children with pains were less by 1 to $2 \mathrm{lb}$. than those of the controls; the numbers of older children were too small for definite conclusions. In other respects, including height, there were no apparent differences.

\section{Intelligence}

For the assessment of intelligence we relied on school reports, based on the child's ability, progress and attainments. On this basis children are allocated to one of the school educational 'streams'. We have presumed that errors inherent in such a method are equally applicable to both groups of children and do not affect the validity of a comparison between 
them. Table 5 shows that the two groups are almost identical.

TABLE 5

INTELLIGENCE ASSESSMENT

\begin{tabular}{|c|c|c|c|c|c|}
\hline \multicolumn{4}{|c|}{$\begin{array}{l}\text { Educational } \\
\text { Stream }\end{array}$} & \multicolumn{2}{|c|}{$\begin{array}{l}\text { Percentage in Children } \\
\text { With Pains }\end{array}$} \\
\hline $\begin{array}{l}\mathbf{A} \\
\mathbf{B} \\
\mathbf{C} \\
\mathbf{D} \\
\mathbf{E}\end{array}$ & $\begin{array}{l}\ldots \\
\cdots \\
\cdots\end{array}$ & $\begin{array}{l}\cdots \\
\cdots \\
\cdots \\
\cdots\end{array}$ & $\begin{array}{c}\cdots \\
\cdots \\
\cdots \\
\cdots\end{array}$ & $\begin{array}{r}20 \cdot 8 \\
28 \cdot 3 \\
32 \cdot 5 \\
16 \cdot 6 \\
1 \cdot 6\end{array}$ & $\begin{array}{r}21 \cdot 2 \\
28 \cdot 0 \\
32 \cdot 1 \\
16 \cdot 3 \\
2 \cdot 2\end{array}$ \\
\hline
\end{tabular}

\section{Emotional Disturbances}

From information given by the parent, schoolmaster and child, we compared the frequency with which some common complaints which might reasonably be attributed to emotional disturbances occurred in the two groups of children. Table 6 shows those groups in which there was a significant difference.

TABLE 6

SOME EXPRESSIONS OF EMOTIONAL DISTURBANCE

\begin{tabular}{|c|c|c|c|}
\hline Disturbance & & $\begin{array}{l}\text { Percentage in } \\
\text { With Pains }\end{array}$ & $\begin{array}{l}\text { Children } \\
\text { Without Pains }\end{array}$ \\
\hline 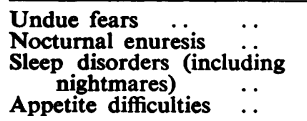 & $\begin{array}{l}\cdots \\
\cdots \\
\cdots \\
\cdots\end{array}$ & $\begin{array}{l}27 \\
20 \\
39 \\
37\end{array}$ & $\begin{array}{r}10 \\
8 \\
18 \\
21\end{array}$ \\
\hline
\end{tabular}

Among appetite disorders we inquired particularly about milk-drinking habits, because of the suggestion that excessive milk drinking may be associated with abdominal pains. We found that children with pains tended to drink not more, but rather less than the controls. In other respects, like nailbiting and tics, there were no apparent differences.

\section{Personality}

From the information available we tried to group the children with or without pains according to their personality traits. The findings are summarized in Table 7.

TABLE 7

PERSONALITY TRAITS

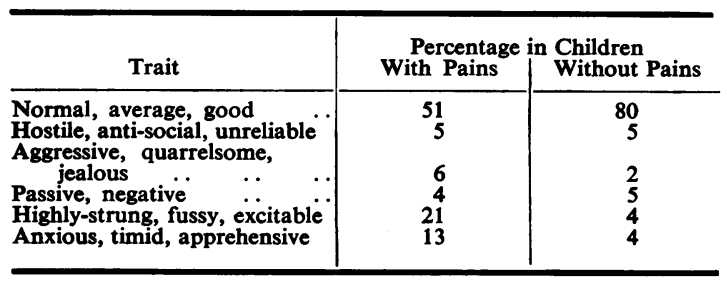

As compared with the controls, many more of the children with pains tended to be highly-strung, fussy, excitable, anxious, timid and apprehensive. We formed an impression of over-conscientiousness in many children with pains, and also in their parents. More of these children, too, were said to be 'bad mixers' ( $23 \%$ as compared with $15 \%$ of the controls).

\section{Electro-Encephalography}

With the cooperation of the parents we took this opportunity of obtaining E.E.G.s from many children without pains and comparing the findings with those of children in the same range of ages but with recurrent abdominal pains. E.E.G.s were obtained from 202 school children without pains and 97 with pains (Table 8). The reports, both on children with abdominal pains and on the controls, were made by Dr. E. C. Turton without knowing into which group they fell.

TABle 8

REPORTS ON ELECTRO-ENCEPHALOGRAMS

\begin{tabular}{|c|c|c|}
\hline E.E.G. Record & $\begin{array}{l}\text { Percentage } \\
\text { With Pains } \\
\text { (No: 97) }\end{array}$ & $\begin{array}{l}\text { in Children } \\
\text { Without Pains } \\
\text { (No: 202) }\end{array}$ \\
\hline  & $\begin{array}{r}74 \\
12 \\
0 \\
0 \\
4 \\
10\end{array}$ & $\begin{array}{r}74 \\
9 \\
0 \cdot 5 \\
0 \cdot 5 \\
1 \cdot 5 \\
14 \cdot 5\end{array}$ \\
\hline
\end{tabular}

In the epileptiform group were included all definite and borderline cases, whether in resting or evoked (photic stimulation and hyperpnoea) records. The classification of normal records was based on accepted descriptions for children (e.g., Henry, 1944). Children with a history of fits were included: there were two with abdominal pains (neither had had fits for several years) and 12 without pains (including three continuing under treatment for fits).

\section{Discussion}

Incidence. The high incidence of recurrent abdominal pains in our unselected school population confirms the impression that this is one of the commonest of childhood complaints. Our material was drawn from working and lower middle class families, in a thriving town with a population approaching half a million and negligible unemployment. We have no means of comparing the incidence with that in either agricultural communities or in the higher social and financial scales.

Naturally, the incidence must vary according to the criteria used in the selection of cases. Ours 
were chosen with the object of ruling out trivial and transient disturbances, on the one hand, and, on the other, serious organic disorders which would be expected to have become manifest in the time limit we set. The series of children with pains proved similar to another series of children referred to hospital with the same complaint (unpublished data). The significant differences found were that in children attending hospital because of abdominal pains the proportion with severe pains is slightly higher, there are more 'only children', and there are proportionately fewer girls in the pre-pubertal agegroup.

On these grounds we consider that our conclusions are, in the main, applicable to the vast numbers of children with this common complaint.

Age Incidence. The age incidence and the age of onset of pains in our series set some interesting problems which remain to be solved. In the early years the curves for both sexes are similar, suggesting that the underlying factors are the same for both. It is of interest that the peak occurs at the age when schooling commences. From the age of 8 years the pattern diverges markedly in the two sexes, and the onset of puberty in girls might be postulated as an additional factor. From our data we cannot confirm or refute this possibility. As between girls with or without pains, there was no disparity in the time of development of secondary sex characters; and the number in whom the menarche had occurred was so small as to be non-contributory.

Organic Disorders. It is obviously important to determine or eliminate organic disease as a cause, though in many large published series the proportion of children with a demonstrative causative organic disorder has been shown to be small. In the present study, on clinical examination we found no appreciable physical differences between children with or without pains, other than a slight disparity in average weight. Even this may reasonably be related to the appetite disturbances which are commoner in children with abdominal pains.

The figures for epileptiform abnormalities in the E.E.G.s of our two groups lend no support to the notion that the recurrent abdominal pains which are so common in childhood are an expression of epilepsy without fits.

Emotional Disorders. Under this heading fall the significant differences between our groups of children with or without pains. Children with certain types of personality seemed commonly affected. They were timid, nervous, anxious or over-conscientious- just the types of children in whom emotional disturbances would be expected to develop. In children with an underlying predisposition school or other difficulties often seemed to have a 'trigger effect' in evoking pains.

Family History. High though they are, our figures for the incidence of abdominal pains in the families are almost certainly an underestimate. We have found elsewhere that the proportion of positive replies increases if the number of interviews is increased and the parents are given better opportunities to remember. But even as they stand the figures illustrate the continuing thread of disorder in successive generations. Our data contribute nothing to the fascinating problem of why perhaps only one among several children, with a common family background, should develop abdominal pains.

The relatively high incidence not only of functional but also of organic abdominal disorders in the families of children with pains is of great interest. Is it that these 'abdominally minded' families are more thoroughly investigated? Have these families a predisposition to abdominal disorders of different sorts? Does functional disorder develop into organic disease? In this connexion we mention two parents who, like their children who were in our series, had complained of abdominal pains in childhood, and who now suffer from peptic ulcer in adult life. Similar examples will probably occur to most doctors, but they must be considered and weighed against the high frequency both of abdominal pains in childhood and of peptic ulcers in adult life.

\section{Conclusions}

We set out to compare children complaining of recurrent abdominal pains against children without them, in a large, unselected group of school children. In our survey three subsidiary points were established: First, the high incidence of recurrent abdominal pains, especially at certain ages and particularly in girls. Second, the high incidence of abdominal and certain other complaints in the families of affected children. Third, the negative evidence of any physical association with the pains, and the positive evidence of frequent emotional disturbances.

Children with abdominal pains tend to fall into certain categories as regards personality and emotional patterns, so much so that often one can forecast which children are likely to develop the symptoms. Often when difficult situations are imminent, as at the beginning of school terms or examinations, the occurrence of pains can be correctly predicted. As compared with other 
children, those with pains tend to be anxious, timid, fussy and over-conscientious, taking the ordinary difficulties of life (especially of school life) too much to heart.

We gratefully acknowledge our indebtedness to Dr. A. L. Smallwood, Senior School Medical Officer, and other School Medical Officers in the Bristol area, and

to the Chief Education Officer and his staff, including the headmasters and headmistresses who cooperated so generously and made our survey possible, and to Dr. E. C. Turton for the E.E.G. reports.

\section{REFERENCES}

Henry, C E. (1944). Monogr. Soc. Res. Chi!d. Dev., 9, No. 3 (Serial No. 39). 